\title{
Exploring Impediments to the Proliferation of Commercial Unmanned Aerial System (UAS) Use in the National Airspace System (NAS) of the United States
}

By

Darren Spencer, University of South Florida

The UAS industry is experiencing a rap- A collection of industry experts was interid expansion, doubling every year since viewed to discuss the UAS industry and to ex1 2013, as adopters of this disruptive plore these perceived obstacles that may be hintechnology find new ways to benefit from these aerial platforms (Spencer, 2018). Of particular interest is the use of small to medium sized UASs, with a cost to the user of less than $\$ 2,000$ that are the catalyst for this growth. Despite this rapid dering an increased use

Unmanned Aerial Vehicles (UASs), best known as Drones, are expanding in their use, but not as fast as expected. The interviews analyzed here help us understand why UAS use has not reached its full commercial potential growth, UAS operators claim an inability to of experience in UASs, and at least 10 years in use these systems to their full potential due to aviation to provide a breadth of experience and regulatory obstacles. array of viewpoints.

Keywords: Unmanned Aerial Vehicles, Aerial Photography, DJI, Drones, FAA, Disruptive Technology, Aviation, Law Enforcement, Emergency Response, Agriculture, Construction.

Copyright ( 2018 , Muma College of Business. This article is published under a Creative Commons BY-NC license. Permission is granted to copy and distribute this article for non-commercial purposes, in both printed and electronic formats 


\section{Introduction}

Despite the explosion of popularity of UASs, and the recognition that such systems must find a way to safely operate alongside manned aviation, a literature review by this author as well as interviews with three commercial aerial photography companies in Tampa Bay, Florida, indicate that regulatory restrictions are still the greatest obstacle to law abiding commercial UAS operators. It can take six to eight months with a backlog of 12,000 waiver applications to get either a Part 333 or Part 107 exemption, which grants FAA permission for a commercial operator to fly a UAS inside controlled airspace (Gardner, 2018). A manned pilot can file a flight plan and hover a helicopter over the same area in just a few hours.

The purpose of this research was to determine what industry experts perceive the future of UAS regulations will be, and how the industry will be impacted in both the short term of 5 years or less and longterm of 5 years or more. UAS industry expert interviews were conducted in the "reflection of the meaning," semi-structured style, with each interviewee given the latitude to discuss topics as they came to mind. A preset approved bank of questions helped to guide the interview, but in many cases as experts in the field, the interviewees naturally discussed the topics covered in the preset questions and the interview adapted to avoid unnecessary repetition. One interview was conducted in-person, but the rest were via phone calls due to geographical separation.

\section{Interviewee's for this Study}

Twelve individuals were interviewed for this study and included over 206 years of aviation experience combined. Interviewees averaged a little more than 17 years per interviewee, with even more professional experience outside of aviation. The highest member had 50 years of aviation specific experience in a

\section{Methodology}

The interviews were conducted in the semi-structured interview format. Although an attempt was made to keep each interview as similar as possible to each other, there was variation as interviewees discussed their experiences. Some subjects kept their answers brief, while others gave more elaborate answers which tended to lead into discussions that would have been asked at a later point in the interviews. There were initially 15 interviews planned for this study, but as they progressed and the 12th interview was completed, the answers from the subject matter experts became repetitious and saturated. As a result, the interviews were halted, and an analysis of themes ensued.

variety of roles, while the lowest had just two and a half years (see Figure 1).

Although the initial goal was to interview from three categories, it was found that the experience of the experts in the field did not easily fall into the defined categories. As a result, the initial three categories were expanded to four, since they did not portray the industry as accurately as desired. In many cases, an academic was also a legal or regulatory expert, or an operator was also a regulatory representative. Instead of categorizing interviewees into one specific classification, the following chart was created to better show their expertise and backgrounds. An individual was assigned a value in each area based on their level of experience, with a total possible score equal to years of aviation experience (see Figure 2).

The four categories were each represented by interviewees, with the charts in Figure 2 and Figure 3 better depicting their backgrounds than a simple categorization would. The pie chart in Figure 3 shows the cumulative experience based on years of expe-

\section{Interviewee Years of Aviation Experience}

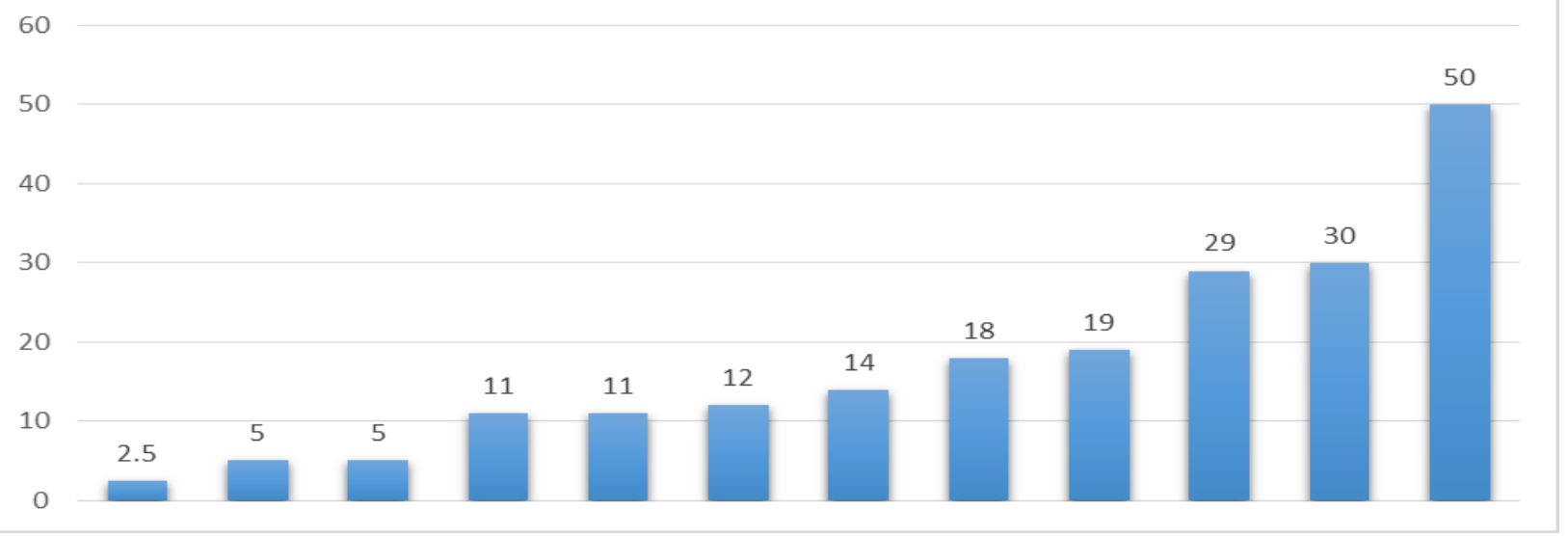

Figure 1: Interviewee Years of Aviation Experience 


\section{Interviewee Experience Distribution}

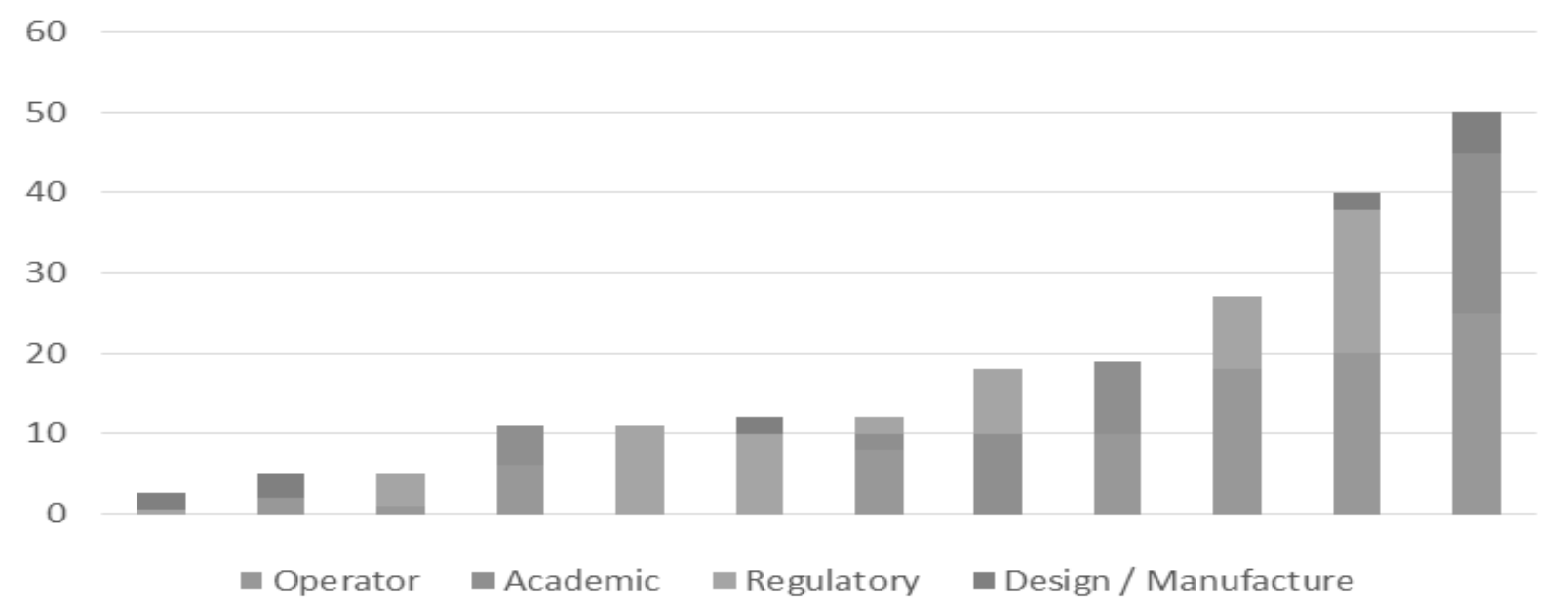

Figure 2: Interviewee Experience Distribution

rience in each of four categories, but does not differentiate the quality or diversity of this experience as it is impossible to measure given this study's limitations. Based on this author's 18 years of aviation specific experience and educational background, he finds this dispersion of experience to be a highly valid representation of the UAS industry as it relates to regulatory issues (see Figure 3).

Each interviewee is listed below with a brief biography highlighting individual experience.

Interviewee 1: An Associate Professor at Embry-Riddle Aeronautical University and a certified corporate pilot with over 5,000 flight hours.

Interviewee 2: President of a consulting compa-

\section{Total Experience Distribution}

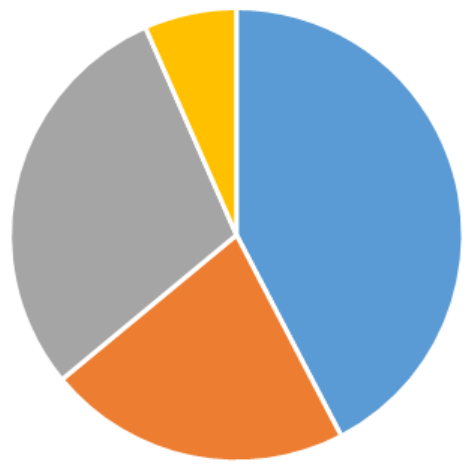

- Operator $\|$ Academic $\backsim$ Regulatory $\|$ Design/Manufacture

Figure 3: Total Experience Distribution ny, former Professor of Aviation with six years devoted to unmanned systems, member of several FAA-sponsored aviation rulemaking committees and practicing attorney for 28 years.

Interviewee 3: Assistant Professor of Aeronautical Science with seven years in the U.S. Air Force.

Interviewee 4: Team member at the UAS Integration Office Research Division of the Federal Aviation Administration (FAA) with experience working with the U.S. Navy in manned and unmanned aircraft.

Interviewee 5: Editor in Field at an online UAS news company, member of several Federal Aviation Administration's small unmanned aircraft systems aviation rulemaking committees.

Interviewee 6: Director of Commercial Drone Services at his company and member of the National Board of Directors for AUVSI. A former pilot for the Navy.

Interviewee 7: Business Development Executive at his company with 50 years aviation experience. Experience as an instructor and corporate pilot.

Interviewee 8: Corporate Communication Director for UAS manufacturer with over 20 years of experience as a journalist.

Interviewee 9: President of his company, retired from the Army with a majority of his career in a Special Operations Special Mission Unit.

Interviewee 10: Currently an attorney in private practice, with over 10 years of experience at the FAA with a majority of that in the regulation of unmanned systems.

Interviewee 11: Vice president of Operations at an International Airport with 29 total years of airport management experience. Created first agreement at 
a major international airport in United States to operate UASs, with the cooperation of a major airline.

Interviewee 12: Former Vice President of Regulatory and Legislative Affairs at the American Association of Airport Executives (AAAE).

\section{Discussion}

\section{Interview Questions}

Although each interview had minor differences, each interviewee was asked a foundational series of eight questions. The questions that appeared to give the greatest experiential insight are listed with a short analysis of the combined responses. Extracted answers that relate most closely to these questions are in tabular format for review in the appendix.

Q1. Looking back, is there anything in particular that really sparked your interest in Unmanned Systems, and if so, could you elaborate a bit?

Of the 12 interviewees, two of them, \#4 and \#12, appear to have had a desire and interest in UAS which drove them to acquire specialized skills and knowledge in the industry. With the other 10, their involvement was more by chance or in some instances involuntary, but the recognition of the potential for growth, or the impact of the evolution of the UAS industry was having on their industry, led them to become more involved with UASs.

It shows that there is something other than a love for the technology that is gravitating these individuals to this sector and could indicate that these individuals are not set on the technology itself, but the ability of UASs to provide solutions to problems in pre-existing industries. If this is true, then their perception of the industry is less likely to be skewed by a desire for the industry to succeed and could indicate a high reliability in the quality of their responses during their interviews.

Q2. Where do you see the UAS industry in the next five years, and what kind of things do you see UASs doing as the industry develops?

The results from this line of thought are varied, but most subjects except for \#12 appeared to view the industry with cautious but realistic optimism. Not all interviewees gave specific examples of where the future of the industry may go, and this could possibly reflect the uncertainty that surrounds barriers to growth. Those that did not give specific examples rather focused on technological or regulatory barriers that they expect to be resolved in the next 5 years. Several interviewees, as a part of their answer to this question, raised concerns over regulatory ac- tions that either needed to occur, or may occur in response to an incident of negative consequences, which could play a major role in the ability for this industry to develop to its full potential.

Q3. What are some of the barriers that you think may currently be, or may in the future impede the ability of the UAS industry to achieve this?

Only five of the twelve interviewees stated that regulations or the FAA were causal for the slower than forecasted growth of UASs. The others spoke in terms of technological barriers, and even four of the five that initially stated the FAA was the barrier explained just a few sentences into their answer that this was due to either technological or resource-based challenges outside the control of the FAA. The themes of safety and public opinion ran throughout the responses except for one interviewee, who only spoke about technological issues.

Q4. If you were king for a day, what is the one thing you would change that could enable UAS use to its fullest extent?

Again, only a small portion of interviewees, four of the twelve, mentioned the FAA or regulatory process as the barrier to industry growth. Six of the twelve referenced technological challenges, and the rest referenced safety or public perception issues. Of the six technological issues, the specific challenges addressed varied by interviewee, but each was chosen with the goal of either increasing safety or the perception of safety by the general public. If the FAA was truly the barrier to the growth of the UAS industry, more of the interviewees would have included that in their responses here.

Q5. What keeps you up at night?

In nine of the twelve responses, interviewees felt that a catastrophic accident or incident was the greatest threat to the UAS industry, and only one of the interviewees did not tie their answers back to public perception or public opinion. This congruency of answers was striking and is discussed in greater detail in the thematic analysis section.

\section{Thematic Analysis}

Each interview was evaluated in its entirety a minimum of three times prior to attempting to analyze the resulting themes. The first round of analysis is shown in Figure 4, depicting the frequencies of each theme as determined by this researcher as it occurred in the aggregate of interviews. This included the entire interview, not just the questions discussed above. There was no weight given to the amount of discussion on the topic, but only a count of the num- 


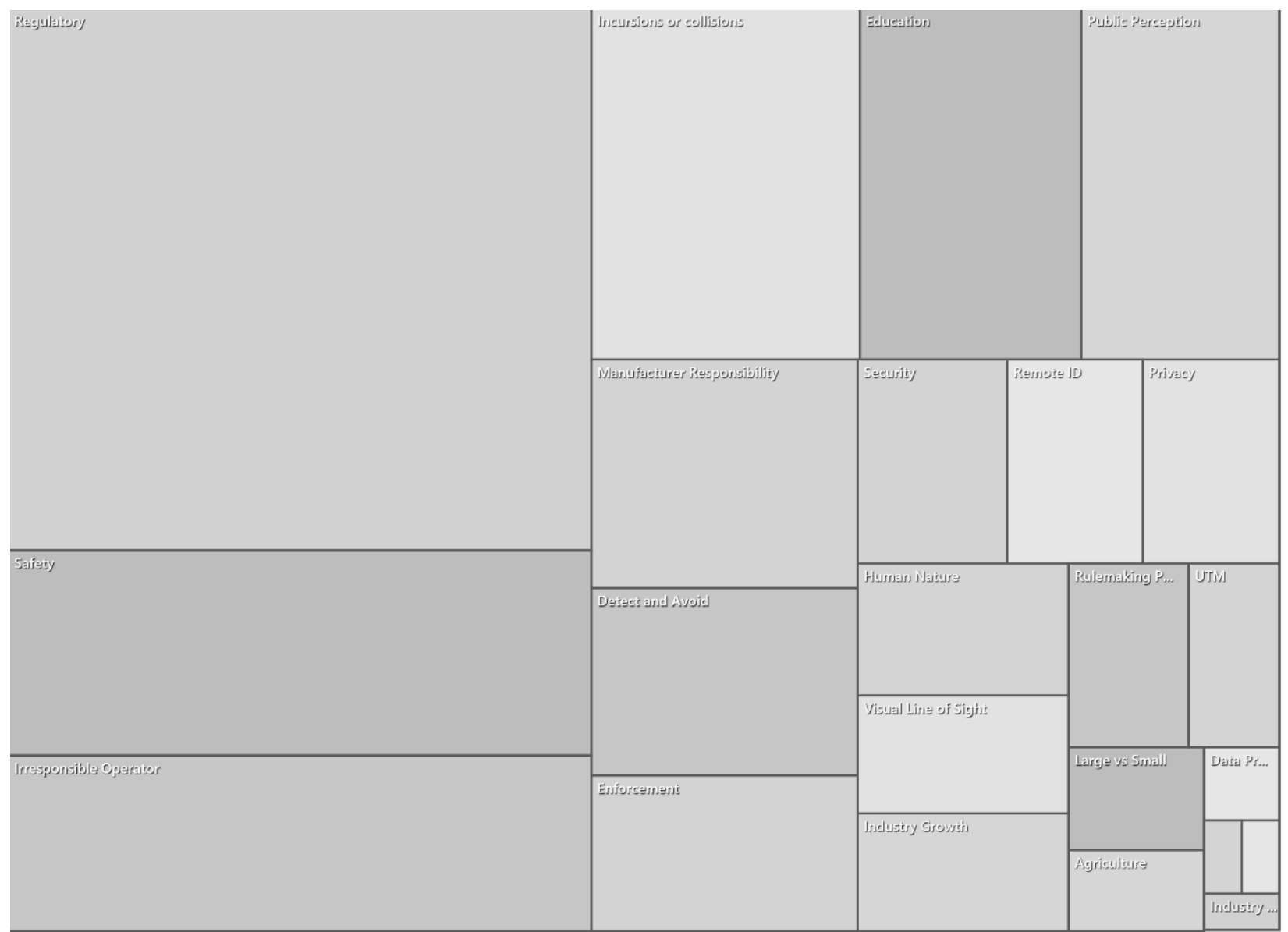

\section{Figure 4: Round One Theme Analysis}

ber of times the topic was addressed by the interviewee.

Through theoretical saturation, the themes were then reviewed to hone down to the core properties of the themes. Three central themes emerged through this process: regulatory, safety, and public perception. To narrow down to these three, all themes were assigned to what appeared to be the root concern addressed by that item. The three themes of agriculture, data processing, and future did not fit in any of the three categories, but did align with other categories that were appropriately paired with one of the three central themes and were thus absorbed. The tally for the final analysis is shown in Table 1.

At first look, it appeared that the safety related themes may fall under the auspices of regulations, and thus be categorized under regulatory. After closer examination of the interviewee's comments related to these issues, the concern for safety went well beyond just the codification of rules and thus the separate central theme. As for public perception, it was both an issue of safety and regulatory, but added a perception and understanding element that transcended both. Acceptable safety standards are determined by the public, and then can be codified into law, but these are generally well defined by measur- able criteria. Public perception of the different types, missions, and even intent of UASs and their operators is a more malleable topic that requires additional research that is well beyond the scope of this research and is thus ill-defined here and requires a separate central theme.

Manufacturer responsibility is the one theme that appears in both the safety and regulatory central themes, since the comments in these coded sections were variably undecided and undefined by the interview subjects in a way that lent this subject to both. Every mention of manufacturer responsibility dealt with determining the best ways to provide acceptable safety, and the reasons for this were centered on either the preemption of regulatory action, or the desire to get regulatory action on the topic. The determinant factor for which way the comments went appeared to be dependent on the professional alignment of the individual, which may or may not indicate any influence, and needs additional research to determine if this is in fact true.

No matter what the issues discussed by interview subjects, their perception of the industry was that explosive growth and dispersion of UAS technology was inevitable. The rate of growth expected though became debatable, depending on two conditions. 
Table 1: Theoretical Saturation Analysis

\begin{tabular}{|l|l|}
\hline Regulatory & \\
\hline & Enforcement \\
\hline & Security \\
\hline & Privacy \\
\hline & Rulemaking Process \\
\hline & UTM \\
\hline & Industry Evolution \\
\hline & Industry Growth \\
\hline & Model Aircraft \\
\hline & Manufacturer Responsibility \\
\hline & Intellectual Property \\
\hline & \\
\hline & Irresponsible Operator \\
\hline & Incursions or collisions \\
\hline & Detect and Avoid \\
\hline & Human Nature \\
\hline & Remote ID \\
\hline & Visual Line of Sight \\
\hline & Manufacturer Responsibility \\
\hline & \\
\hline Public Perception & \\
\hline & Education \\
\hline & Large vs Small \\
\hline & Industry Representation \\
\hline & \\
\hline &
\end{tabular}

The first and most notable was the potential of a catastrophic aviation accident. All subjects who mentioned this were quick to say that it would not stop the industry as a whole, but would significantly alter the growth curve. The second issue only mentioned directly by two of the subjects was the FAA Reauthorization Act of 2018, but the act encompasses almost every issue mentioned by interview subjects not covered under the auspices of a catastrophic accident. This act has provisions within that may upend model aircraft exemptions in section 336, levy fees to UAS users to pay for regulatory oversight costs, create an Unmanned Aircraft Traffic Management System (UTM), and updates sections of Part 107 to allow UASs to carry cargo after meeting still to be defined safety requirements (Rupprecht, 2018). Still under review and debate at the time of this paper being written, these provisions may or may not still exist in the final version, and others may be added.

\section{Conclusions}

It is almost certain that UASs will continue to expand their role in society and find new ways to impact already existing industries that we can still yet only imagine. According to Michael Kratsios, Deputy US Technology Officer, and Executive Assistant of the President, UASs will contribute to 100,000 new jobs and provide nearly $\$ 80$ Billion in economic impact in the next decade (Kratsios, 2018).

What was not clear prior to starting this study is why they are not already filling the skies and meeting the forecasts that called for UASs to deliver items to your doorstep, or lunch to your place of work. Preliminary interviews hinted that the issue was with the FAA, so this grounded theory study to determine what if anything was impeding the expansion of the UAS industry was conducted. After an extensive literature review and background study of the history of UAS regulatory action, the research continued with semi-structured interviews of 12 leading industry experts, with a combined 206 years of aviation experience.

Although the technical backgrounds of the individuals interviewed varied greatly, the themes of regulatory and safety were recurring and present in all 12 interviews. While these resulting themes are understandable given both the findings of the preliminary research and the interview questions posed, the strength of a third theme, public perception, was slightly unexpected. Eleven interviewees spoke about public perception issues as one of their greatest concerns for the proliferation of the UAS industry and gave it the same if not greater emphasis as other themes. In many instances the concern for public perception led to discussion about the regulatory process and how it currently is and will in the future be controlled by public perception. This shows that the FAA is but a part of the equation, and although the most visible and obvious target of frustration, not the actual root concern of those in the UAS industry.

The FAA is the agency responsible for creating laws that impact aviation operations, but regulations are written in response to public opinion. The resulting regulations are the product of lawmakers, not the FAA, and are more influential and important to the overall growth of the industry. Three of the interviewees mentioned the complexity of the rulemaking process separate to any discussion surrounding just regulatory issues in general. Interviewee 10 was the best versed in the overall process and spent over 12 minutes at the end of the interview explaining how complex the Federal rulemaking process was. He emphasized how all agencies from all departments are involved with every legislative action, no matter what their expertise was in the matter being considered. The FAA thus is but an enforcer of the 
will of the people, and most people do not understand the UAS industry.

One of the greatest misunderstandings of the industry is that there is a significant and professional separation in the UAS industry between those operators who comply with regulations and ensure they operate within the confines of safety, and those that carelessly operate without regard to either. As one interviewee put it, "The safety and security professionals whether it's Aviation Safety, National Security, Homeland Security, local law enforcement... they all want someone to be able to remotely identify drones and quickly determine which, if any, are either demonstrating malicious intent or are not complying." These non-compliant operators expose the general public to unnecessary risk, invade the privacy of others, pose security risks, and significantly influence the people who create legislative action.

Every one of the 12 interviewees mentioned these issues as factors slowing the growth of the industry, and each is a regular topic of discussion at UAS conferences across the United States. These concerns impede the growth of the UAS industry as regulatory evolution is slowed by discussions surrounding them, and thus the compliant operators are slowed down by the non-compliant. For the industry to experience the growth potential it has, it must solve the public perception issue.

Future research to determine the current public sentiment toward UASs and what contributes to this is needed. This research may help to identify areas that the industry can focus on for change or an improved public image to allow for UAS growth. Armed with this knowledge, the professional operators may be able to separate themselves from those that operate recklessly and allow the UAS industry to finally reach the potential that Michael Kratsios and other experts have discussed.

\section{References}

Gardner, S. (2018). Flying in the National Airspace System. 2018 FAA UAS Symposium, Baltimore, $M D$. Retrieved from https://www.faa.gov/uas/resources/event archive/2018 uas symposium/

Kratsios, M. (2018). Day 1 plenaries. 2018 FAA UAS Symposium, Baltimore, MD. Retrieved from https://www.faa.gov/uas/resources/event_archive/2018_uas_symposium/

Rupprecht, J. (2018). FAA Reauthorization Act of 2018 \& Drones. Retrieved from https://jrupprechtlaw.com/faa-reauthorization-act-of-2018

Spencer, D. W. (2018). Umanned aerial systems. Muma Business Review, 2(7). Retrieved from http://pubs.mumabusinessreview.org/2018/ MBR-2018-02-07-083-104-Spencer-UAVs.pdf

\section{Review}

This article was accepted under the constructive peer review option. For futher details, see the descriptions at:

http://mumabusinessreview.org/peer-review-options/

\section{Author}

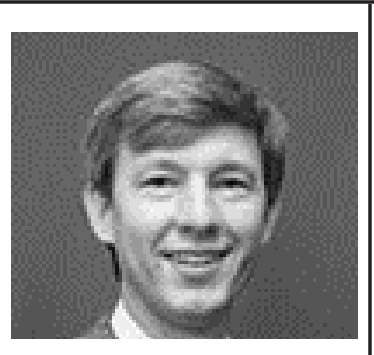

Darren Spencer is is a recently retired United States Air Force instructor pilot who now leads the Air Force Junior ROTC program at Jefferson High School in Tampa, Florida. He is also an Adjunct Professor with Embry Riddle Aeronautical University. Prior to this, he held roles as chief of innovation, deputy chief of the air advisor branch, and assistant operations director at Ramstein Air Base in Rhineland-Palatinate, Germany. Spencer earned a BS BA in Management from Hawaii Pacific University, an MS in Aviation from the University of North Dakota in Grand Forks, N.D., and an MA in Management from the Harvard University Extension School in Cambridge, Mass. 


\section{Appendix: Interview Responses}

\section{Q1. Looking back, is there anything in particular that really sparked your interest in Unmanned Systems, and if so, could you elaborate a bit?}

$\# 1-.$. how I ended up in this area is that I was formerly a corporate pilot. But my education, my graduate
education led me into the remote sensing aspects. I cross-teach in both unmanned aircraft systems and
aeronautical science. I feel like it gives me a unique perspective with students seeing them on one side in
manned aviation and then the other side, the unmanned aviation, and where they clash with automation
issues or regulation and detect and avoid. All the different dynamics that are melding the two together
right now.
\#2- I've been in commercial unmanned aircraft for about 15 years. I got into it as part of an existing busi-
ness. I was a remodel contractor and I'd already been doing hobby stuff for whatever else, digital cameras,
put them on the planes, fly them around, aerial photography of the construction sites, condo projects, real
estate

\#3- Well, it's one of those things that as your experience in the Air Force is probably similar; as somebody's looking for volunteers, and you stick out your hand, and it sounds like it would be something interesting to do, and next thing you know you're embedded so deep you can't get out of it. That's what happened...

\#4- The primary interest for unmanned aviation came from the fact that, really, we're seeing a rebirth of aviation. So, 1903, the first heavier-than-air flight with the Wright brothers. We're seeing a complete rebirth, where this is the first really, truly new thing in aviation since the early 1900s. And that fascinated with me because we haven't figured everything out yet. In fact, we've figured very few things out. That's one of the things I love, is the ability to go into a new element of the industry and try to figure out, how do we do this? And how do we do this safely?

\#5- No, not particularly. It's just something that, I guess, has been building more and more momentum as I've been going throughout my career. I mean, it was always strong on the DoD side, but then working over in the FAA side, it's something that's definitely been gaining more and more steam as the years have gone by.

\#6- Well we saw internally, that our...most of our revenue is derived from Navy contract efforts, so in the federal business world, if we're tied to federal contract, and that's a good news, bad news story. There's not much diversification in it, so as DOD budgets go, so goes private industry that supports that industry. Military efforts, specifically, Naval Aviation efforts. So if a major program that we were supporting gets whacked, and whacked meaning budget reductions or program termination or a number of other things, we're gonna be subjected to that ripple effect of how it flows down through everybody that supports that particular weapon system or that contract. And so the company wanted to diversify, we already do drone work for the military. We do a lot of manned aviation work for the military, mostly Naval aviation. And so, it was a natural fit to then grow our commercial side of the business and use the experience we have in the highly credentialed and certified aviators that we have in the business, and use them for potential job opportunities for the commercial drone world.

\#7- No, just the opposite. I really had zero interest in it 13 plus years ago. Well, actually, probably closer to 16 years ago because he started trying to woo me into this business way back before I was even ready to consider it. I guess, to be perfectly frank, I got into it more out of my friendship for Steve. His company needed help, my background was in flight training and flight operations, and he desperately needed someone to kinda get things back on track for him. So after 30 years with the university they were getting ready to change presidents, and I'd already been through five of them, I didn't really feel like going with another so I basically spit the hook. I was a tenured full professor there, along with being a VP. It was just time to make a change. I had no particular interest in unmanned systems at all.

\#8- [I] was recruited to join DJI. I don't have a traditional tech background or experience in tech PR, per se, but a lot of my background is in dealing with the governmental issues that arise with complicated policy questions about new technology. That's increasingly an issue facing drones, how they're going to be regulated by the FAA, how drones how to be considered by Congress, others in government as a matter of providing appropriate protection, protecting safety and security in that sense as well as regulatory questions about who ought to be able to fly, where and how. 
\#9- I realized that we needed a differentiator to set us apart from the other companies, and that's when we started really looking at bringing in small, unmanned aerial systems into our core area of expertise. We would blend the unmanned aerial systems with what we do for specialties in Intelligence, IT, Cyber Security and Special Operation Forces training. It would be important to leverage the operational integration piece and really focus more on type I and type II size UAVs, which are under 55 pounds, non-program of record type aircraft.

\#10- I was with the FAA prior to that for almost ten years. At one point, our office needed somebody, I was in the chief counsel's office. Our regulations group needed someone to work with our unmanned aircraft systems office. At that point then I was the- worked primarily on drones for the last three years at the agency and was the liaison between the UAS integration office and the chief counsel's office and worked on a lot of the... on the 333 exemptions, on a number of different policies and practices that the agency developed.

\#11- In my position here in DFW, I was just really the point person for a lot of UAS activities. And the reason I ended up in that position is because of my knowledge of air traffic control procedures, 7110.65 specifically. And trying to look at FAR Part 107 and how it's applicable to UAS operations in a Class B airspace environment.

\#12- Well, it's really simple. At triple-A E, I was responsible for operation, safety, planning, emergency management, experimental aircrafts, environmental services, general aviation, UAS, ARFs, airport rescue and firefighting, among a number of other topics. So, while my passion is really in UASs, my job really was quite broad and it was difficult to maintain the focus and to keep on the cutting edge of the industry with having to keep track of so many other things. It was really about a passion for unmanned aircraft systems and integration of policy associated with it., and just wanted to be able to focus more on that.

\section{Q2. Where do you see the UAS industry in the next five years, and what kind of things do you see UASs doing as the industry develops?}

\#1- so you can see how that's dynamically changed over time. Five years ago, it was probably 97\% DoD. Now it's $97 \%$ civilian sector, and those DoD applications are still there, but we see all these technologies coming over...

When you look at growth with linear infrastructure, vertical infrastructure those are the areas where we're going to see growth. Now, looking down range into the future, then we start enhanced capabilities and that technology from larger aircraft integrating into some of the manned platforms that we have. Manned aviation is becoming more and more autonomous. It's already in everything, self-driving cars and self-driving trains, and everything. I think that airplanes are going to be no different in that respect.

We're going to see that technology being integrated into smaller aircraft and then ultimately large transport category aircraft. I think it will follow in some ways the same route that deregulation did with integration, through proof of concept and then integration into normal, mainstream air carriers. That is, of course, down the line, but I think it's inevitable that's going to occur.

\#2- I think the industry has a lot of promise. I think that we can do a lot more and we can use this technology to do a lot of the things that you hear about as far as we are concerned. I'm going to say this though. Drones are not magical. I don't think drones are going to be the cure all and fix everything we want them to fix. It's just the business models just not there and I think people have been a little bit over optimistic. They've hyped it too much. I don't think we'll ever reach all of those goals. However, they will help us be better stewards of a planet with diminishing resources, help us feed a hungry world, things like that. I think that's really where the promise is, like drone delivery and burrito delivery and stuff. I mean, its novelty or whatever. I don't really need a drone to deliver me a burrito. I don't really think the Amazon model makes sense.

\#3- It's happening now in a way. I mean, there's experimental programs for the package deliveries. They're talking about taking medications or other emergency material out to a remote area, like on an Indian reservation or out in the country someplace or in the forest where somebody might be stranded or lost. They're doing that on an experimental basis. The other more practical uses such as power line or pipe line inspections, building inspections, construction and then on the public safety side, law enforcement agencies using unmanned systems for search and rescue, for accident reconstruction. They're not supposed to be using them for surveillance or even evidence collection, but they're using them extensively for backup for night operations. 
I think you're going to continue to see a growth in the use of the systems in an industrial side where they're ... I just got off the phone a couple hours ago with a client that's going to do power line inspections they're seeking a waiver of one specific section of part 107 to be able to fly their aircraft without a visual observer on the ground. That's not an impossible challenge for me. I'm sure we'll get a waiver for that from the FAA but, the arguments for using this kind of a system as opposed to having a human being climbing up a power pole or a cell phone tower is that, I think the last statistic I heard that in one year the telecommunications industry had 70, I think this was four years ago, 72 or 76 deaths of men, from primarily falling off of towers doing inspections. One death is unreasonable but 72 is just outrageous. They want to put an end to that and they wanna use these systems to be able to conduct the required inspections of these infrastructure without endangering lives. That's where the growth is gonna be is using the systems that are really too dangerous for a human being.

\#4- The big thing on everyone's lips right now is the Beyond Visual Line of Sight authorization, which is the ability to fly beyond just the local area of the operator. I think that's going to come out within the next five years, probably within the next two to three years, if we're realistic.

I think, once that element of the industry is flushed out, we're going to see some really dramatic growth, primarily because you have industries that want to perform deliveries and do other sorts of functions, that can't be done close-by to an operator, so that ability to have that remote operation taking place is one of the key. I think once that happens, we're bound to see even more growth than what we're at, and, if I remember correctly, and I don't know if I have the statistics right off the top of my head, but we're looking at an industry that is going to be in the billions of dollars in the next several years. And I don't think that that's going to be the ceiling. I think it's only going to continue to expand as the regulatory structure allows it to.

\#5- That's a difficult one, because it really depends on what rules we can get in place, but with one of the new presidential programs that we're working on, I see us actually working and accelerating some of that integration in specific areas of the country, so I think in the next five to seven years, you'll actually see some trial package deliveries out there, and also more integrated, I guess with different industries, that rely on UASs that I am thinking of, like insurance and then search and rescue. I think UAS will be used a lot more often. It'll be a semi-regular thing to see in certain parts of the country.

\#6- I see a continued push towards greater levels of automation. So there will be an ability for a drone in a box type scenario. That's the most simplistic example where you push a button, the box opens up, the drone takes off and flies an inspection of an industrial facility. Whether it's for security or whether it's using sensors on more the drone to detect leaks or a number of things, then the drone returns back to it's nest or box, lands and recharges. Or swaps payloads and goes back up, flies it again. That entire flight operation is with minimal human in the loop intervention. Maybe zero, maybe other than pushing the button that says go. Maybe the entire operation is almost fully automated.

\#7- [Consumer use] I've always been of the belief that particularly at the consumer lever, these systems that FAA and others have been so nervous about, the volume of that activity will clearly wane... there's clearly a decline.

[Professional use]... what you are seeing though is increase. A fortunate increase of the use of these systems for legitimate professional reasons. Using them to save lives. Using them to collect information that can better mankind. Doing the kinds of things that they were designed to do. The hobbyist, the recreational user community. I always categorize these things much like the old pet rock. Its new technology, everybody loves it, its really cool when it first comes out, but how many pictures of your roof can you take? After a couple of flights, these things go into closets. They're just not out there. But the professional users, that's the ones we really want to concentrate on. I think you're clearly going to see that shift in the volume of activity and the makeup of that activity to far less recreational and far more professional in its application.

\#8- It's easier to see the increasing automation, actually the increasing capabilities on the hardware side. Drones that can fly faster, farther, in worse weather that have better sense and avoid capabilities, et cetera. In many ways the bigger challenge for widespread adoption of drones in enterprise uses is what happens with the data they generate because a drone flying in automated routes is a data collection business. A job site, for example, is going to be gathering an awful lot of data over time, a lot of imagery that has to then be downloaded from the drone, uploaded either to a desktop computer or to a cloud server, or the processing that comes from that and the organization that captured the data. How does it manage that? What if you're a construction company with a fleet of 12 drones and they're out flying every day? How do you start gathering all that together, providing smooth work flows? 
\#9- So there are so many things that are going to happen. It's very similar to the invent and proliferation of the internet globally or cell phones when they came of age. You and I know that it was in, I don't know what year, we had the bag phones we had in our cars that not that many people would use, because they were so expensive and they were big and heavy and people thought, "Why would you need something like that?" Now, you can't live without them. If you walk out the door without your phone, it's more important than the keys to your car. So it will be similar, only on a much grander scale, with UAS technology. I don't think it's just UAS technology, I think it is all things unmanned, internet of things and artificial intelligence. So all of those things combined are going to make tremendous advances over the next 5, 10, 20 years. I think what we're going to see is not just the UAS technology that will continue to advance, I think concurrently there will be mass distribution of product and services being used by unmanned systems on a commercial scale. There will be much greater militarization of unmanned systems in the battle space. President Trump recently signed into law H.R. 5515, the John S. McCain National Defense Authorization Act for Fiscal Year 2019, authorizing the U.S. Department of Defense (DoD) to spend \$9.6 billion for unmanned vehicle systems. The bill increases military spending for unmanned technologies by 28 percent over last year, according to an analysis by the Association for Unmanned Vehicle Systems International (AUVSI).

\#10-I think the short term is going to be linear inspection when that use becomes regularized when there's some finally some regulation or some other way that allows routine use of beyond line of sight and over people that a construction company can survey their site while their workers are continuing to work and don't have to shut down operations or go into off hours for the electric utility, inspecting the power lines, pipelines, and the lights. And I think that within the next 3 years that will become routine and I think that's the short term. The long term we're talking about- I don't know, that's kind of an open question. Its been so much focus on this immediate need, right, and small UAS, but I think there's starting to be some look at flight within larger vehicles, flight within intermingling with manned aircraft at the flight levels or other places. I guess implementing systems to make that possible. So, whatever that looks like, as you know, anything that you can think of and more can be done with a drone. So we're not yet, haven't yet discovered all the potential uses for them.

\#11- You're going to see a lot more of those applications, pretty much video and still photography. I know that utility companies are going to use the UAS to inspect the pipelines and transmission lines. That is applicable for a high density metro area. I know there's companies inspecting the top of these wind generators at several hundred feet above ground, but those obviously are going to be nowhere near the airport area.

But there are a lot of practical commercial applications within five miles of an airport. And as you go out a little bit farther, when you get out of that five mile ring, the FAA is allowing you to fly up to 400 feet. I know that the package delivery services are very interested in initiating service, especially when you're getting overnight deliveries to an airport facility and then trucking to a warehouse that is in very close proximity to an airport to sort and further disseminate for distribution in a local area. I don't know if the FAA's going to move that quickly to allow that type of operation, because that's getting closer and closer to core airport operations.

\#12- I think we're trying to catch fire in this industry. This is the type of disruptive technology that really needs to hit that critical mass. And when you look at it, there are a couple of major components. One of those is the automation technology. Do we have... the technology for automation and aviation and on ground vehicles? The answer is, were just about where we need to be right now.

I actually think once you put that automation technology in the air, it becomes much simpler. There's many fewer variables and scenarios that AI has to contemplate in the air. In addition to that, we've already have seen a high degree of autonomy in manned aviation, especially at the airline level. We're not quite there to where we need to be, or not quite where we need to be. We will be very soon. And we'll absolutely be there by the time, ten years from now

[Different question same theme] Ten years from now I think we'd like to see widespread utilization of UAS: flights over people, medical and public safety, widespread public safety flights, and then also package delivery, things of that nature. I think that's very, very attainable inside ten years 


\section{Q3. What are some of the barriers that you think may currently be, or may in the future impede the ability of the UAS industry to achieve this?}

$\# 1$ - The regulatory aspects are one thing. We've got other things, we have to worry about when you have widespread integration of UAS technologies that mixing. We have what? 37,000, roughly 37,000 commercial flights a day. You've got to figure out how that affects overall operations in not only the airspace above 400 feet, but the airspace below 400 feet. I think they're taking initiatives of that.

But other things that they're looking at besides just the commercialization and the ability to grow with operations are the security aspects, the detect and avoid issues are considerable, and other things that affect the movement of UAS technologies in the mainstream environment are based on society's perceptions and things like privacy and acceptance of automation, those types of things.

$\# 2$ - I got to be honest that the 107 from what I knew and from what I was doing on the ARC was very liberal. I thought it was very liberal that mainly I was surprised that there was no practical test for the license. Say that anybody could go buy a 55 pound aircraft or like a ScanEagle and fly it around at 100 miles an hour and they don't even have to prove that they knew how to fly that thing is dangerous in my estimation...

The other thing that needs to be done is I think that the community needs to get real. The other thing, and I had this conversation earlier this morning, someone was saying "Well, you know, it doesn't seem like the drone thing is really panned out" like the forecast of 82 billion dollars and all the rest of it and until we get beyond visual line of sight. Well, people want to fly over people. People want to fly beyond visual line of sight. The engineering, or the meantime between failure numbers on the aircraft are way too low to really think that you're going to be flying over people or being able to fly beyond visual line of sight and there were people that were telling people that in $2015 \ldots$

$\# 3$ - Well that's really the $\$ 64,000$ question. Probably the major impediment is the FAA. I don't mean that as a criticism necessarily, but they were overwhelmed, the agency was overwhelmed and is still overwhelmed by the demand for the use of unmanned systems in a domestic environment, in non-military or non-security. They were not equipped both with man power and just resources to deal with what was going on. There were folks that were out there flying these airplanes really without any regulatory oversight at all and the FAA tried to step up with some policy statements and other ways of trying to enforce their existing regulations. They've behind the curve for quite a long time in developing a regulatory scheme that would address the demands of the industry itself. By the industry I mean, everybody that's out there selling and flying and servicing these aircraft. Against the concerns of the public, invasion of privacy is one of the major concerns for the smaller aircraft and the potential for disaster.

There's a lot of, unfortunately been literally thousands of incidences of people flying multi rotor aircraft or quad copters in airspace that should be occupied by commercial aircraft. They're trying to get up close to an airliner on approach into an airport and that hasn't led to a disaster yet, but the fear has been all along that one day some idiot's gonna fly one of these things into the engine of a large commercial jet and it's gonna cause a catastrophic accident that would bring the aircraft down. That'd shut everything down.

\#4- I think the biggest thing is going to be data. There's a GAO report that was recently published that criticized the FAA, saying that they're making some decisions or UAS policy based decisions, without data... but the number of individuals, the number of contributors of data to help the FAA move forward is minimal. It's needed. And so, as I think we generate more of those data points, to show that either the system is working, or the system is not working, will allow us to move forward as an industry.

[Separate question, same theme]...I think the best way to codify that would be non-compliant operators. And basically, there are rules in place that the FAA has already codified, about who can operate UAS, for what purpose, and when. And how. And so all of those rules make up either 14 CFR Part 107, the Part 333 Exemption process, the Part 334 process for public operators, or Part 101 for hobbyists.

So, the problem lies in when you have one or more of these different stakeholders that don't follow the rules that the FAA has laid out, and now you have a non-compliant operator, which basically means they are the ones producing the threat to the national airspace system. And everyone throws up their hands, saying, well, what do we do about these guys? Because a policy or rule may not necessarily be the change that's necessary.

And so those are the people that are really holding up the industry, because, even if they create the right rules, if people don't follow them, we're still at the same point we are before, which is an unsafe national airspace system. 
\#5- ... some of the technology isn't actually there. For the most part, the detect and avoid aspects, they are not where they need to be for autonomous operations or for UAS operations. Then the autonomous piece of operations is another problem, because we see what happens with cars today and they've halted most operations of autonomous vehicles because of the accidents that they've had, and we don't want the same thing that happened with UAS. You've gotta be very cautious of what the public outcry is for the autonomous vehicles for driverless cars, and look at that piece for UAS as well.

\#6- So until we get remote I.D. figured out, until we gain the trust and confidence of the security apparatus there in that particular location of the country, then I don't see civil operations under Part 107 occurring any time soon.

[Separate question, same theme]...It's being able to ensure that the system's levels of air ordinance are at the levels that are equivalent to manned aircraft in the eyes of the FAA. So until we can ensure that quad copter's motor will not fail at the inappropriate time and cause problems, then there will be greater challenges for us to prove and demonstrate a safety change, or whatever particular operation we're trying to fly. So air ordinance is a consideration. The other one is, kind of embedded in that, is operations over people. So right now, the FAA-and this is all regulatory if you haven't picked up on it. The other one is being able to prove that air ordinance is at such a high level that, even if there was a failure, statistically, the level of damage or the potential for cause of harm to humans or infrastructure or structures in general, is minimal and at an acceptable level. So, operations over people is a challenge.

\#7- we got to solve a few technical challenges. We've got to ... the FAA is ... much like doctors. First do no harm. You could disrupt a piece of technology in the airspace like an unmanned system. Unless you have ways to accommodate and mitigate the risks associated with that, you're going to have a hard time selling the concept. We all want see and avoid, detect and avoid, the 90-1113 requirements. Those are huge. How do you keep one of these things from running into an airplane or being in a place where it shouldn't be? There are challenges there. Particularly when you talk about size, weight, and power issues associated with them. One of the things a lot people forget is that the real product that these systems provide is data. Its not the airframe. Its not the aircraft itself or the system. So much time and effort is spent on developing the platforms and building something that can carry the hardware to satisfy a detect and avoid requirement on the vehicle. And unfortunately, a lot of that is sacrifice of its ability to collect data. The products, what we're really trying to sell.

\#8- Sure. Look, I think everyone needs to recognize that Part 107 was a big step forward for the FAA. It was only a few years before that that they were equally as suspicious of unmanned systems and requiring over the top levels of certification and training for people just to fly relatively small systems. They now fully appreciate the potential for unmanned systems. They're also trying to balance an awful lot of interests. They have said a truly horrible potential incident involving a drone will set the entire industry and all the good that it can do back by years. If that happens, everyone who can appreciate the benefits of them loses. They need to ensure that their safety remains the most important value for safeguarding your own interests.

\#9- One of the big problems, a big part of all of this, are the rules, laws and legislation surrounding it. What are we doing here in the U.S. to stay advanced of other countries, to keep our technological edge when these other countries may have less restrictive rules, laws and legislation on pilots that we don't allow? Does that then put us behind in technology, because we're not creating the air worthiness or the air systems that are going be able to control how these things will work effectively? So all of those things will be concerning, they're already concerns. Some other big things to consider are personal rights and your right to privacy. That's one of the problems that we have right now with new legislature, policies and laws, and restrictive rules for law enforcement.

\#10- Resources is why. The regulator is, is focused right now on the short term but important gains need to be made in overflight of people. So that's one right? There's only so much capacity they can handle especially as their so tied up with doing waivers and exemption requests, and things like that. And so as that they cross the hurdle of, especially ops over people, the overflight, the waiver requests should drop off, bring up more resources. That's one. The second one is really data. That is one of the challenges of the FAA or any agency, any technical agency when their doing rule making is being able to justify, in a rule, what the bases of the standards are putting in place. Why is it safe? How do we know? That's part of it from what side steps that issue by saying we're going to limit the altitudes of flight. We're going to require people to fly not over people, I guess. You have to have a license or a special requirement. Only fly during the day. You can't be in a controlled air space. They put those safety parameters around the operation and kinda put a buffer around the operation so that- because there really wasn't the data to say, "we know it's safe to fly up to 800 feet because of the amount of aircraft" or "we know it's safe to fly over people because" right? 
\#11- The number one item that's going to hinder the growth of the UAS is the individuals and the very few folks who don't follow the rules, don't care about knowing the rules, think they can fly their UAS anytime and anywhere they want. And unfortunately, that rogue operator is going to probably be responsible for an incident that's going to cause restrictions and rules, and really temper down the integration of UASs in the airspace system.

There's people out there that go out and buy a unit and they buy a GoPro. They attach it to it, they don't know the rules. If they're given the rules, they don't care. And off they go, and they just want to operate their UAS, thinking that nobody owns the airspace when in fact, the FAA does.

There is going to be the one individual who has not taken the time to educate themselves on the rules and regulations associated with operating UAS. They're going to be the ones that are going delay integration not only here in the metroplex, but all over the country. Because if something happens, if that incident that we hope doesn't happen, if that happens and there's significant structural damage or loss of life, there's going to be restrictions put in place nationwide.

\#12- [Paraphrased from comments] Automation Technology, Aviation Technology, and Integration Technology

Q4. If you were king for a day, what is the one thing you would change that could enable UAS use to its fullest extent?

\#1- Well, from a prioritization, I think that it does fall to detect and avoid problems. You have ... Detect and avoid goes hand-in-hand with regulation obviously. When we started to expand our capabilities to operate near controlled airspace or controlled airspace and in some cases with the proper approvals, but we still don't necessarily have a sense and avoid or a detect and avoid solution that's going to give us positive assurance that no UAS equipment is going to hit a manned aircraft.

\#2- My thing with it is, is if you're not going to start making examples of these people no one's going to pay attention to your rules but even worse than that, the FAA looks foolish. We can't enforce what we already have.

\#3- It would probably be the airspace management piece of it. To come up with some magic algorithm that would virtually guarantee that a UAS could not under circumstances come into contact with a manned aircraft through any kind of a sense and avoid or detect and avoid system onboard the aircraft or a combination of ground based sense and avoid while airborne. They're working on it, sensor packages are in development from a variety of sources to try to solve the sensitive void part of it both in compliance with the regulations and just from a practical sense. NASA's got their UTM program on that aircraft a traffic management system that they're trying to develop a way to manage and then just integrated traffic so that there's no conflicts so that everybody's flying within a designated corridor so that conflicts are avoided.

\#4- I think the pace at which the FAA is willing to implement change is slow, and its well below what the industry is ready to do. I think the industry is ready to help make those cases for further expansion of unmanned aircraft into the national airspace system. But I think, to answer your question, if I had a magic wand today, I would change the organizational culture of the agency to match that of the industry. Because the industry is moving at the pace of innovation, and the FAA, kinda understandably so, is, well, barely moving. I think there's concern about making the right decisions, because the industry is chomping at the bit to continue to evolve. And the FAA is very much holding them back at the moment, in my opinion.

\#5- The one change that would make everything a lot easier in the airspace would, if all airspace in the US was cooperative. We have uncooperative participants, because uncooperative versus cooperative means that everybody has to communicate where they are at all times, and has to send information back and forth to all the participants. If all airspace in the US was like that, it would be a lot easier to actually integrate drones, because then you know where everything is, and you can have your separation distances and be fine. But that's not the way that airspace works in the US, unfortunately.

\#6- Batteries. Our lithium polymer batteries have not changed in technology since the 70s when they were first mass produced and so, there's been a better effort of making them more efficient in the form factor that they're provided for, for these small drones. But our number one limitation in the field is that battery, so I could be much more efficient, I could do much more data collection if I had a stinkin' better battery, but they have not come yet. So, as a result, when I deploy into the field, I have to purchase lots and lots of batteries, which are expensive and they all have a shelf life. 
\#7- They're all a lot of little things I guess. I think it probably would be a better recognition or appreciation by ... I keep beating on the FAA, but what a great target. That they recognize that they are not the end all be all in terms of expertise...

... If those barriers were suddenly removed and we could do the kinds of things that we really know we are capable of doing, I would be happy. That would be a good thing.

\#8- Look, the safety and security professionals whether it's Aviation Safety, National Security, Homeland Security, local law enforcement. They all want someone to be able to remotely identify drones and quickly determine which, if any, have either are demonstrating malicious intent or are not complying with a remote identification monitoring system. There are authorities that want the ability to say, "Shoot down or disable," a drone that's not compliant with this system. It's a power that we certainly understand why governments would need that in the most extreme situations, but it brings with it an enormous number of complications. If government, say, shoots down a threatening drone and it lands on somebody, who's responsible? How do you apportion blame for that? How do you handle that? All the sorts of questions that have been worked out over decades for other types of technology.

[Different question same theme] ... That's increasingly an issue facing drones, how they're going to be regulated by the FAA, how drones are to be considered by Congress and others in government as a matter of providing appropriate protection, protecting safety and security in that sense as well as regulatory questions about who ought to be able to fly, where and how.

\#9- I think it's important that the populace has more knowledge. So organizations like AUVSI are very good, because it helps to bridge the gap by bringing more information to our government leaders who can then better understand from the perspective of the pilots in the industry. AUVSI aides to spotlight what capabilities are out there and what government restrictions have on our pilots in relation to the evolving technology.

\#10- I think that if they can solve the data, if they can generate good data, especially if they can make a rule making and draw lines that have a rational bases that are supported by evidence, then they'll be in good shape.

\#11- There's always going to be a set of individuals that either A, think the rules don't apply to them. Or they're knowledgeable about the rules and think they're not going to get caught, so they just carry on because it's more convenient to them. That's going to be a real issue here if a drone operator is aware of the rules but says, "You know what? It's really cool to take this up at 3500 feet and go above an airplane and take a picture of it, because that's what I want to do."...

...Unfortunately, it's probably going to take somebody operations a drone to bang one off an airplane, get prosecuted for it, and put in jail to show that law enforcement and the government agencies are serious about enforcing rules and regulations that are for the safety of the flying public. I hate to think that would happen, but human nature says there has to be consequences, known consequences and communicated consequences, for people to change their behaviors after the fact. If you don't get a speeding ticket, you're going to continue to drive 80 to 90,100 miles per hour because it's my road. Everybody else needs to get out of my way.

$\# 12$ - It could take the APA and throw it in the trash. The Administrative Procedures Act. That's the one thing that turns a six-month process into a three-year process. That's absolutely, positively not gonna happen. So I don't even know if it's worth mentioning. But I would say that some keys that I think are actually attainable that really could fix some of the problems, one of them would be remote ID and tracking. That's a really, really, important rule. And if we get it right, that will unlock the door to a lot of the other regulatory issues we need to tackle. But there needs to be some sort of accountability associated with these operations. That way, the public ... Again, where the public comes into play is the security agencies, law enforcement, and so forth. It will give them a higher degree of comfort in this technology if they know that there is accountability associated with these operations. So remote ID and tracking is really, really important. That's one. 


\section{Q5. What keeps you up at night?}

\#1- Well, of course, with growth in the number of systems and the growth in the number of people that are buying them, the biggest thing then that I worry about is the increase in the likelihood of an incursion, right? An incursion that could have substantial impact. Luckily, the things that we've seen to date haven't had a huge impact on manned aviation. However, when we do at some point, if we do at some point see some type of UAS activity causing mass casualties as a result of irresponsible operations or just uninformed operations then it's going to be disastrous for the industry.

\#2- Well, I don't know. It'd be hard to say what the biggest issue is. I think they're all fixable and it just requires the industry to get serious and act like business people. I think what you're going to see happen is the data thing is going to correct itself because there's too many people offering drone services but the quality of data that they're getting is about the same so when people start to realize that the better quality data is going to get you a more professional wage I think that will fix itself. The regulatory thing, I don't really see that fixing itself. There's a motivation issue...

... enforcement needs work. The other stuff, the beyond visual line of sight, all the rest of that, the industry has a lot of work to do if they want to do all that. I think it's doable too. You're just going to have to use science and it'll be baby steps. When you have an aircraft that's quasi reliable then we can talk about flying over people, stuff like that so I think mostly they'll fix it. The real stopping is the regulatory side of it.

\#3- Security. The largest manufacturer, commercial manufacturer of unmanned systems in the world is a company based in China, DJI. They collect data, operations data as the aircraft are being flown. I have one of their systems that I've just fooled around with. I don't do it for pay or anything like that but I bought one just so I knew what I was talking about and if you log on to the app and operate the aircraft connecting to their system then they're collecting all that data including video images. DJI denies that they're doing anything with that data and that they have any interest in analyzing whatever it is that's being collected. I'm not sure I believe that. That's a worry.

\#4- the non-compliant operators. In the area of research that I specifically focus in, we're seeing a number of trends and visual sightings of unmanned aircraft by pilots, which basically is, not a direct barometer, but I'll call it an indirect barometer of a lack of safety in the national airspace system. In other words, drones and pilots are coming into closer contact with each other, where they shouldn't be.

\#5- Well, it's always the people that you can't regulate, and the people that just will go out there and do whatever they're gonna do with the drone, because they don't think it's gonna cause any harm at all, and we've seen a couple incidents where it has caused ... Well, thankfully it hasn't caused any deaths or anything like that, but it has caused harm. There was an incident in North Carolina where a helicopter pilot, they were on a training exercise and a drone came out of the treetops and they had to maneuver away, and they ended up crashing into, I think, the helicopter because of it.

\#6- statistically it's going to be a catastrophic event. Meaning, there's fatalities involved because of a drone. Or at least that's how the news will report it. Worst case scenario would be a commercial airliner is hit by a drone as the commercial airline is taking off or landing at an airport, and is unable to recover so lives are lost. And it is determined that the drone was where it should not have been. It most likely as a result of a recreational operator who just did not have the awareness or the understanding of the air space and was flying somewhere where that person should not have been flying their drone. And as a result, much like we've seen with the autonomous ground transportations, with the Tesla's, anytime there's a fatality in one of those vehicles, even though there's tens of thousands of hours in those vehicles with zero incident, it just takes one to really put the industry on its heels.

\#7- Yeah. We certainly don't want the ... one of the thing we ... I just came out of a board meeting with AUVSI last week. We talked about messaging should the balloon go up and one of these things hit an airliner and kill 200 people. Is there a possibility that can happen? Yeah, with some of the knuckleheads that are out there flying these systems in places they should not. That always looms out there. Should it occur, how much of a setback is that going to be for this industry? How do you manage that message? How do you ... again it gets back into that public perception discussion we had earlier. How do you convince the public yeah we just lost 200 lives, but over the course of ten years how many lives did these things save? There's risks with everything. 
\#8- I'm more worried about what are the policy implications if there is a decision that makes it suddenly very difficult for people to use drones either for fun or for beneficial professional uses. The overwhelming majority of drones are flown safely and responsibly. People want to do the right thing. They don't want to create a hazard. They don't want to create a privacy problem. They don't want to alarm anybody. They don't want to bother anybody. There will always be outliers. There's going to be outliers with anything. But the evidence to date shows that this is an astonishingly safe technology that an awful lot of people enjoy.

\#9- I can take somebody that we interviewed to come in as a pilot who has never been a UAV pilot before and teach them, and actually, they can self-teach within a day or two by giving them basic expectations; "These are the things that you'll have to know and understand before we can consider you". They have the ability to go and purchase parts and pieces for very low cost to create a flying system and if they know anything at all about homemade explosives, they can create a remotely operated munition. They can weaponize that aerial system and they can cause an International incident with only a week's worth of study through material provided on the internet. So that, to me, is very concerning. The reality is most anybody could do that.

\#10- I think it's that safety and security piece. How do you prevent sorts of action like- drones present such a- think about a situation where somebody can have sort of drones or handful of drones in the truck of your car and drive somewhere and launch them out and do something with them that's nefarious or bad or whatever. How do you prevent that? I think that's the biggest question for me and I think overall too, I mean I don't know what the real risks are but in terms of what the security community says that that's something that's out there. You can access and get to a level of access that you wouldn't have with a manned aircraft or a vehicle, a car, an automobile.

\#11- The easiest one is from an airport operator perspective. It's a collision. And from an FAA perspective, it's a collision. And I have to think, obviously from an airline operator, it's a collision. And to some extent, from a commercial business operator who's operating a UAS in support of their for-profit corporation, that would have to be it, is a collision.

Nobody knows what's going to happen if a drone collides with an airplane. Nobody knows. It might hit it in a non-critical area and bounce off. It might gash the fuselage and the airplane might be perfectly flyable. And I'm just not talking about a Boeing 737. I'm talking about a Cessna 172 carrying a family of four. It also might hit the airplane in the wrong place to render control surfaces inoperable, and then we have an uncontrolled flight into terrain, and then we have some serious issues to deal with.

\#12- The security aspects. There's a couple of ... Definitely the security aspects about it. It is extraordinarily easy and it's almost a miracle it hasn't been done, but someone could very easily attach an incendiary device or worse, biological or radiological payload to a drone, and drop it right in the middle of a stadium. Right now, there's virtually nothing we could do about it. You're talking an incident that could easily cause a massive loss of life. And it would be extremely low-tech. Well, I should say, it's fairly high-tech but it's easily available technology, and at very low cost. Then you could even multiply that by ten or 15 devices easily and create really a mass casualty incident. That, to me, is extremely daunting.

The other thing, similar vein, the nefarious actor that could put one of these things in an aircraft engine, or a swarm of them in an aircraft engine and take down a major airliner with a couple hundred people on board. That's plausible as well. And I think that's a major danger. 